\title{
Five new species and a new record of genus Oncopsis from China (Hemiptera: Cicadellidae, Macropsinae)
}

\author{
Ren-Huai Dai \& Hu Li
}

\begin{abstract}
Dai, R.-H. \& Li, H. 2013: Five new species and a new record of genus Oncopsis from China (Hemiptera: Cicadellidae, Macropsinae). - Entomol. Fennica 24: 9-20.
\end{abstract}

Five new species of the genus Oncopsis from China are described and illustrated: O. cuneiforma sp. n., O. kangdingensis sp. n., O. odontoidea $\mathbf{s p .}$ n., O. serrulota sp. n. and O. spinosa sp. n. Oncopsis kuluensis Viraktamath, 1996 is reported for the first time in China. Distributions and an identification key of all Chinese Oncopsis species are given.

R.-H. Dai \& H. Li, Institute of Entomology, Guizhou University; The Provincial Key Laboratory for Agricultural Pest Management of Mountainous Region, Guiyang 550025 Guizhou, P.R. China; Correspondent author's e-mail: dairenhuai@yahoo.com.cn

Received 25 April 2012, accepted 24 October 2012

\section{Introduction}

The leafhopper genus Oncopsis belongs to the tribe Macropsini (Cicadellidae: Macropsinae). Lauterer and Anufriev (1969) reported 1 new species from China. Hamilton (1980) revised the world Macropsini including 41 species, and later (Hamilton, 1983) described 23 new species from the New World. Kuoh $(1981,1985,1987,1992)$ described 7 new species from China. Korolevskaya (1984) described 1 new species from Tadjikistan, Anufriev and Emeljanov (1988) 1 more from China, Tishechkin $(1992,2008) 2$ from Russia, Liu and Zhang (2003) 1 from China, $\mathrm{Xu}$ et al. (2006) 2 from China, Okudera (2008) 6 from Japan, and Mühlethaler (2008) 1 from Greece. Recently, Liu (2009) described 1 new species from China. Dai and Zhang (2009) reviewed the species $O$. aomians Kuoh, 1981 as Pediopsoides aomians (Kuoh) and Tishechkin (2011) synonymized O. plagiata Kuoh, 1985 with O. obstructa Dlabola, 1963. Accordingly, so far 83 species are known in the world, including 14 species from China.

In our present study, 5 new species, O. cuneiforma sp. n. from Yunnan province, O. odontoidea sp. n. and $O$. spinosa sp. n. from Qinghai province, $O$. kangdingensis sp. n. from Sichuan province, and $O$. serrulota $\mathbf{s p .}$. n. from Ningxia province are described and illustrated. Oncopsis kuluensis Viraktamath, 1996 is newly found in China, Sichuan province. Distributions of all the Oncopsis species known in China are listed, along with a key for identification.

\section{Material and methods}

Morphological terminology follows Anufriev (1967) and Hamilton (1980).

The type specimens of the new species, as well as the rest of the material examined are deposited in the Institute of Entomology, Guizhou University, Guiyang, China (GUGC). 


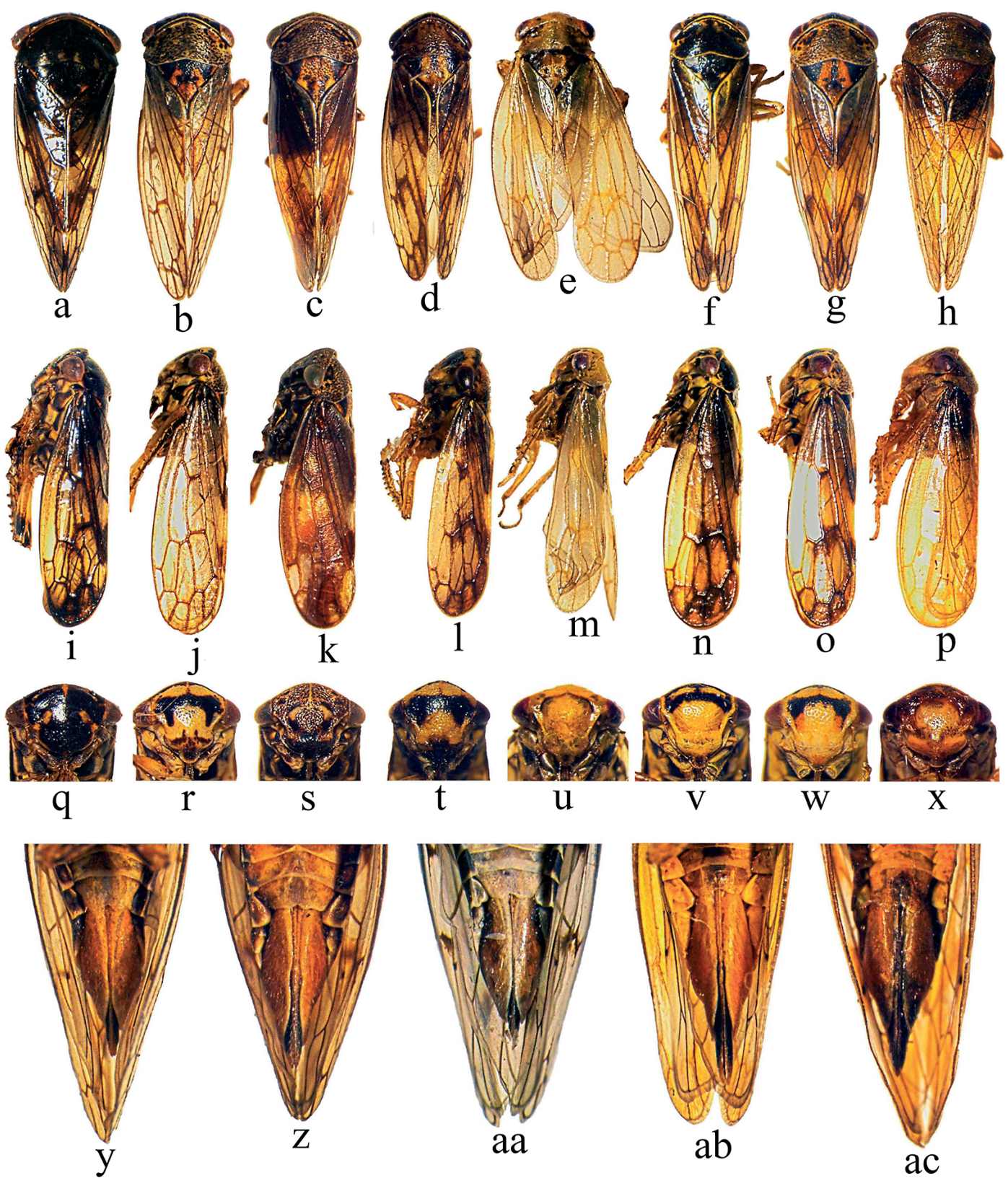

Fig. 1. Male dorsal $(a-h)$, lateral $(i-p)$, facial $(q-x)$, female $7^{\text {th }}$ sternite ventral view $(y-a c)$. - Oncopsis cuneiforma sp. n. (a, i, q) - O. kangdingensis sp. n. (b, j, r, y) - O. odontoidea sp. n. (c, k, s, z) - O. serrulota sp. n. (d, l, t, aa) - O. spinosa sp. n. (e, m, u, ab) - O. furca Liu \& Zhang. (f, n, v) - O. nigrofascianus Xu, Liang \& Li. (g, o, w) - O. kuluensis Viraktamath ( $\mathrm{h}, \mathrm{p}, \mathrm{x}, \mathrm{ac})$.

\section{Descriptions of new species}

\subsection{Oncopsis cuneiforma sp. n. (Fig. 1, Fig. 2)}

Type material. Holotype ${ }^{\Uparrow}$ : China: Yunnan prov., Gaoligong Mountains, Pianma town, 2,450 m,
15.VIII.2006, leg. Tang Yi. Paratype ふ̋: same data as in holotype.

Description. Male. Body (Figs. 1a, i) form stout, cuneiform. Head slightly curved; crown distinctly wider than pronotum; shorter in middle. Face (Fig. 1q) broader than its length, 
Fig. 2. Oncopsis cuneiforma sp. n. - a. Male pygofer lobe and subgenital plate, lateral view. - b. $2^{\text {nd }}$ abdominal apodemes. - c. Aedeagus, lateral view. $-d$. Aedeagus, ventral view. - e. Dorsal connective, lateral view. $-f$. Style, dorsal view. - g. Connective, dorsal view. h. Connective, lateral view.
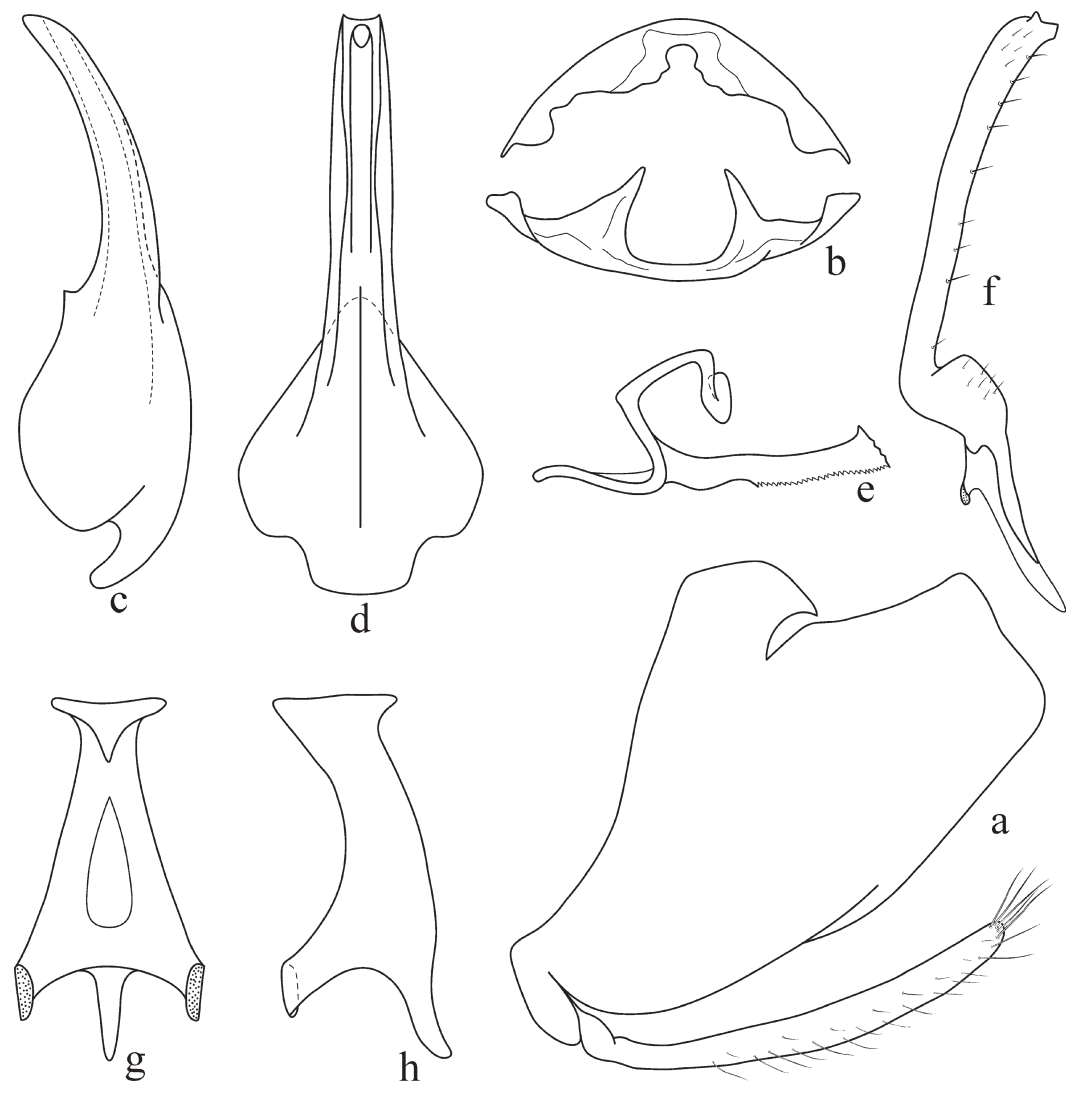

striations look weak because of black background pattern; ocelli situated between eyes, distance between ocelli nearly 8 times as long as that from ocellus to adjacent eye. Pronotum declivous onward and bilaterally, transverse striations weak. Scutellum triangular, with weak transverse striations and with one heavy notch on each side of midline in posterior part, median length as long as in pronotum.

Forewings transparent except painted parts, with 3 anteapical cells. $2^{\text {nd }}$ tergal apodemes broad and short, apex with sinuated margin, $2^{\text {nd }}$ sternal apodemes broader basally and slender, almost parallel with each other (Fig. 2b).

Coloration. Body coloration pattern black dorsally, yellow ventrally. Crown black on anterior margin, yellowish brown on posterior margin. Face with a large black anchor-shaped region, occupying most part of face, remaining area yellow; eyes brown. Pronotum and scutellum for most part black with little yellowish mottles. Forewings yellowish brown, basally and termi- nally dark brown; veins black. Legs yellow, marked with black areas.

Male genitalia. Pygofer lobe rectangular, slightly elongate caudo-dorsally, end strongly truncated, without setae, subgenital plates slender with many marginal setae, end with a bunch of long setae (Fig. 2a). Aedeagus slender, tubular, broader basally, tip blunt in lateral aspect, in ventral aspect slightly concave (Figs. 2c-d). Dorsal connective "S"-shaped, end dorsally reflexed, in middle produced into a long and large handsawshaped process with serrated ventral margin (Fig. 2e). Style slender, with setae, apical half slightly bulbous, tips truncated with an additional projection (Fig. 2f).

Female. Unknown.

Measurements. Length (including tegmen): $\widehat{\sigma}$ (holotype + paratype), 4.6-4.8 $\mathrm{mm}$.

Distribution. China (Yunnan prov.).

Remark. Different from others taxa of Oncopsis by: body form is clearly cuneiform, tapering backward, and dorsal connectives are very dis- 

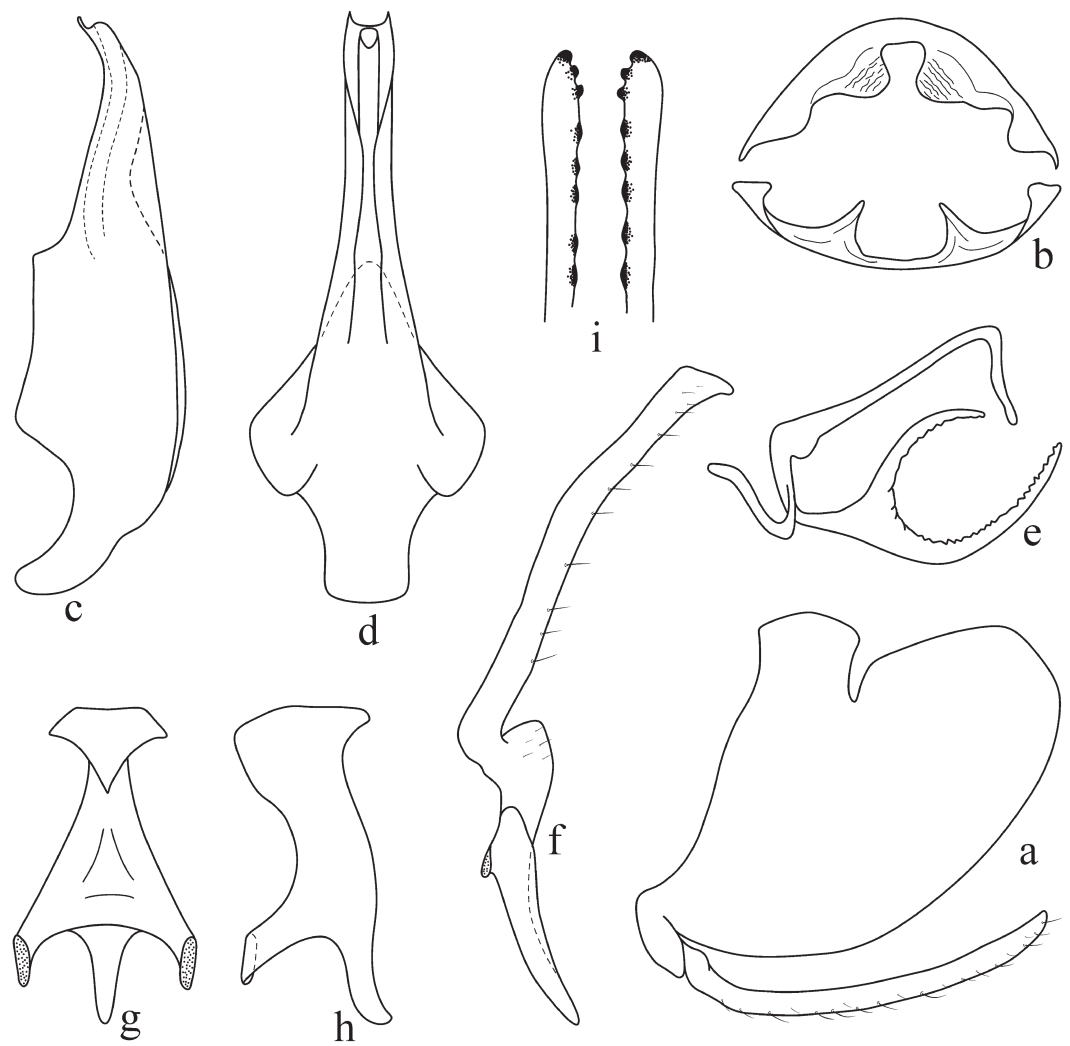

i

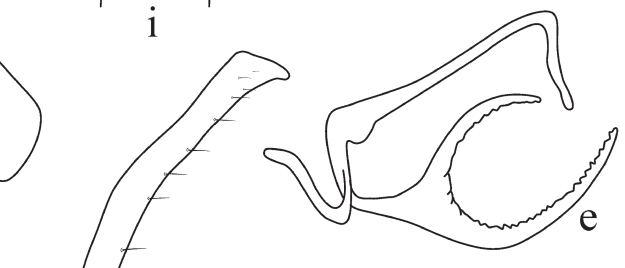

tinct by their long, large and marginally serrated processes like handsaw-shaped, aedeagus also differs in shape.

Etymology. The name is derived from the Latin word "cuneiformis", indicating that the body is clearly wedge-shaped, tapering from head to the ends of fore wings.

\subsection{Oncopsis kangdingensis sp. $n$.}

\section{(Fig. 1, Fig. 3)}

Type material. Holotype ふ̋: China: Sichuan prov., Kangding county, 2,700 m, 10.VIII.2005, leg. Tang Yi. Paratypes, $1 \hat{\circ} 7$ 우: same data as holotype.

Description. Male. Body (Fig. 1b, j; face Fig. 1r) shape and coloration typical for the genus but head shorter, veins brown. $2^{\text {nd }}$ tergal apodemes broad, with weak transverse striations on surface, apex round, $2^{\text {nd }}$ sternal apodemes broader basally, tapering, nearly paralleled (Fig. 3b).

Male genitalia. Pygofer proximately oblong, slightly elongate, ends of the lobes round, subgenital plate slender with many marginal setae (Fig. 3a). Aedeagus tubular, broader basally, shaft slender, apex with a distinct dent, gonopore apical (Figs. 3c-d). Dorsal connective strongly bifurcated in middle, basal part relatively short, tip produced in to two branches, dorsal branch short, twisted ventrally, ventral one longer than dorsal one, twisted dorsally, inner margin serrated (Fig. 3e). Style long with several setae, clearly sinuate, angled on apical third, apex slightly bulbous (Fig. 3f). Connective with finger-like (tip slightly twisted caudo-ventrally in lateral aspect) protrusion in middle, both side arms bend to dorsum (Figs. $3 \mathrm{~g}-\mathrm{h}$ ).

Female. Body coloration and appearance similar to male. Both sides of $7^{\text {th }}$ sternite slightly concave, in midline about 1.5 times as long as $6^{\text {th }}$ one, concave in mid-posterior margin, ovipositor strongly projecting beyond pygofer (Fig. 1y). $2^{\text {nd }}$ valvulae with 5 additional strong teeth, separated by rather long gaps (Fig. 3i).

Measurements. Length (including tegmen): $\curvearrowright$ 
Fig. 4. Oncopsis odontoidea sp. n. - a. Male pygofer lobe and subgenital plate, lateral view. - b. $2^{\text {nd }}$ abdominal apodemes. - c. Aedeagus, lateral view. $-d$. Aedeagus, ventral view. $-\mathrm{e}$. Apex of aedeagal shaft, left lateral view. $-f$. Apex of aedeagal shaft, right lateral view. - g. Dorsal connective, lateral view. - h. Style, dorsal view. $-i$. Connective, dorsal view. $-\mathrm{j}$. Connective, lateral view. - k. $2^{\text {nd }}$ valvulae of ovipositor.
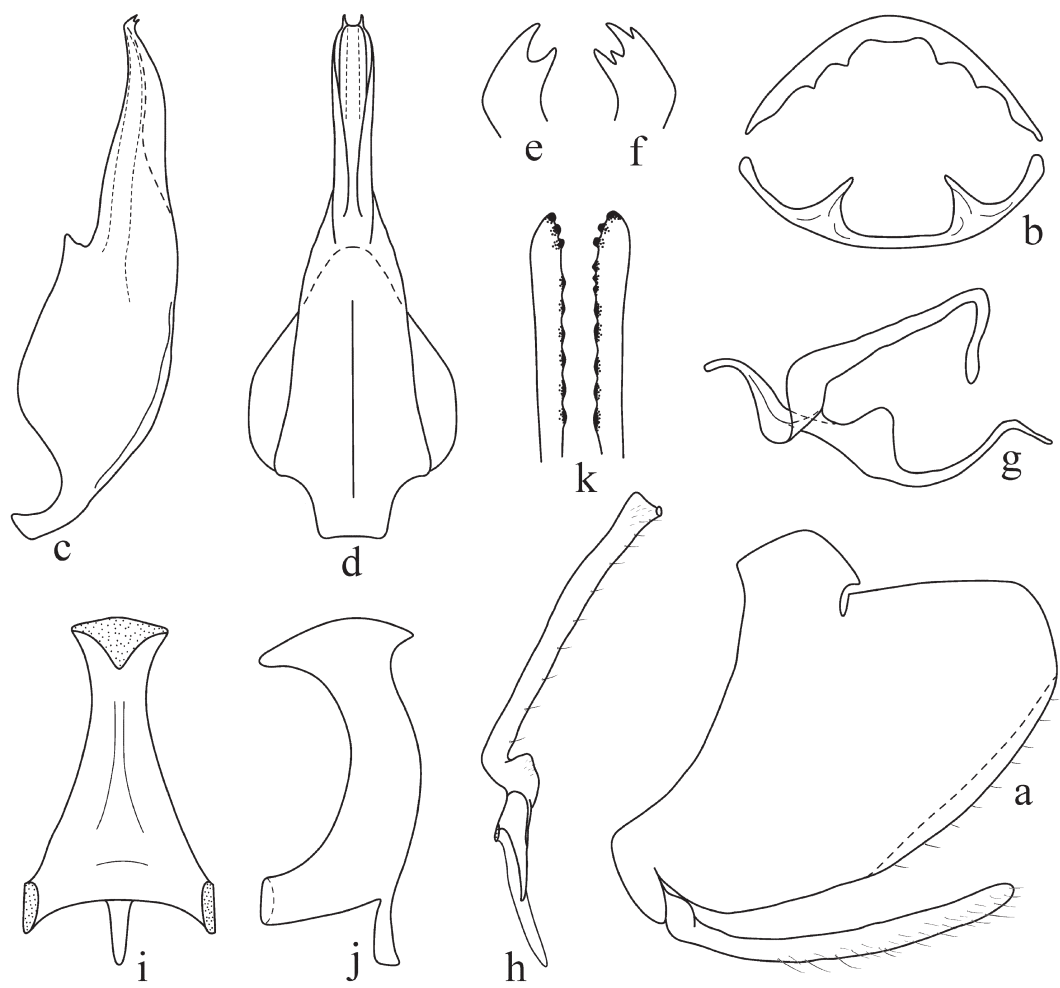

(holotype + paratype), $4.3-4.5 \mathrm{~mm}$; + (7 paratypes), 4.4-4.8 $\mathrm{mm}$.

Distribution. China (Sichuan prov.).

Remark. Nearly similar features with many other species of Oncopsis, but differs from all known ones in the shape of dorsal connectives.

Etymology. The name refers to the type locality, Kangding.

\subsection{Oncopsis odontoidea sp. n. (Fig. 1, Fig. 4)}

Type material. Holotype $\widehat{\jmath}$ : China: Qinghai prov., Beishan, 7.-8.VIII.2009, leg. Yang Zaihua. Paratypes: $3 \hat{\jmath}$, China: Qinghai prov., Xining city, Huangyuan, 2,560 m, 27.VIII.1997, leg. Li Zizhong; 1 ภ 2 우, China: Shaanxi prov., Taibai Mts, 2,500 m, 2.X.1997, leg. Li Zizhong; 1 त, China: Qinghai prov., Xining city, Huangyuan, 13.VIII.1998, leg. Li Zizhong; 1 đ̂, China: Ningxia prov., Liupanshan, 28.-29.VI.2008, leg. Song Qiongzhang.

Description. Male. Body (Figs. 1c, k) stout. Form typical of subgenus Parasitades. Head curved prominently, blunt on vertex, wider than pronotum. Crown narrow. Face (Fig. 1s) rough,

striations distinct; frons with a longitudinal carina; ocelli small, located between eyes, distance between ocelli 4 times as long as that from ocellus to adjacent eye. Pronotum broad, declivous, transverse striations distinct. Scutellum triangular, with marked notches on central region and one heavy notch on posterior region. Tegmina half-hyaline (except several hyaline spots). $2^{\text {nd }}$ tergal apodemes small and weak with serrated margin, $2^{\text {nd }}$ sternal apodemes broad basally, tapering, nearly paralleled (Fig. 4b).

Coloration. Body yellow brown, striations dark. Pronotum with irregular black spots near eyes. Face yellowish brown, with yellow spots symmetrically in middle, surroundings dark; frons with dark brown striations; eyes darkbrown; ocelli yellowish. Scutellum yellow (except dark triangular spots on both lateral regions), marked with black puncta, posterior margin with symmetrical spots. Forewings yellow-brown. Legs yellow.

Male genitalia. Pygofer round caudally, truncate apically, ventral margin with several setae, subgenital plate slender, with marginal setae (Fig. 4a). Aedeagus broad basally, tapering (Figs. 4c- 

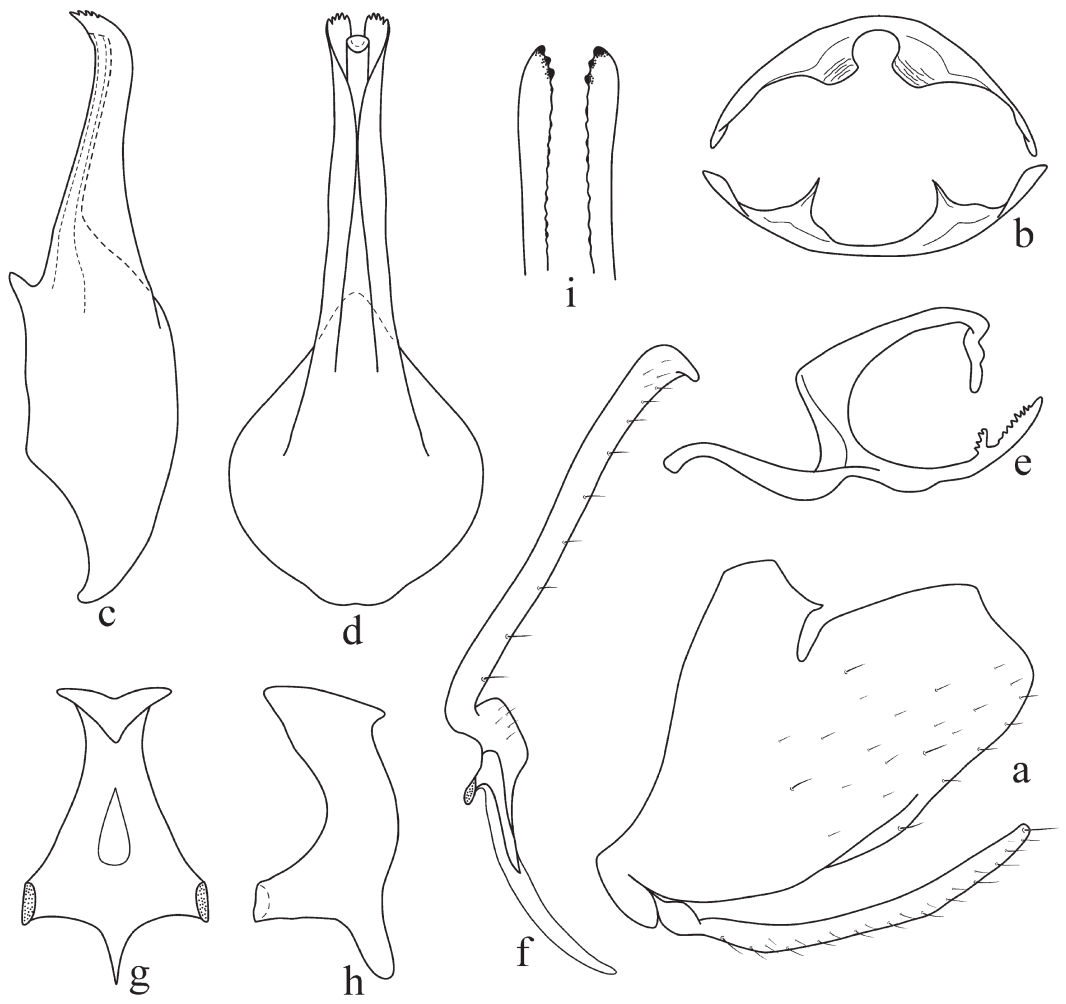

Fig. 5. Oncopsis serrulota sp. n. - a. Male pygofer lobe and subgenital plate, lateral view. - b. $2^{\text {nd }}$ abdominal apodemes. - c. Aedeagus, lateral view. $-\mathrm{d}$. Aedeagus, ventral view. - e. Dorsal connective, lateral view. $-f$. Style, dorsal view. - g. Connective, dorsal view. $-\mathrm{h}$. Connective, lateral view. - i. $2^{\text {nd }}$ valvulae of ovipositor. d), apex of aedeagal shaft with pair of asymmetric serrated processes (Figs. 4e-f). Gonopore apical. Dorsal connective large, strongly developed, bifurcated in middle, upper branch short, nether one slender (Fig. 4g). Style with setae, angled on apical fourth, prominent subapically, tip upturned (Fig. 4h). Connective with a finger-like protrusion in middle, both side arms twisted to dorsum (Figs. 4i-j).

Female. Body coloration and appearance similar to male, but more stout. Midline length of $7^{\text {th }}$ sternite about 1.2 times as long as $6^{\text {th }}$ one, sinuated on caudal margin, concave on mid-posterior region (Fig. 1z), and $2^{\text {nd }}$ valvulae with 6-8 strong additional teeth (Fig. 4k).

Measurements. Length (including tegmen): $\hat{\sigma}$ $(n=7), 3.8-4.0 \mathrm{~mm}$; $+(n=2), 4.0-4.2 \mathrm{~mm}$.

Distribution. China (Qinghai, Shaanxi, Ningxia prov.).

Remark. Similar to O. fusca (Melichar, 1902), but can be distinguished from the latter by: apex of aedeagal shaft with a pair of asymmetric serrated processes; gonopore small; dorsal connective bifurcated in middle with upper branch short.
Etymology. The name is derived from the Latin word "odontoideus", indicating that the apex of aedeagal shaft having a pair of asymmetric serrated processes.

\subsection{Oncopsis serrulota sp. n. (Fig. 1, Fig. 5)}

Type material. Holotype 0 : China: Ningxia prov., Liupan Mountains, 2,050 m, 28.-29.VII. 2008, leg. Song Qiangzhang. Paratype $q$ : locality and date same as in holotype.

Description. Male. (Body: Figs. 1d, 1) Head strongly curved with paralleled margins, slightly wider than pronotum. Striations on face (Fig. 1t) weak, lateral sides of frontoclypeus strongly extended, lora covered, slightly inflated; ocelli situated between eyes, at distance 4 times as long as that from ocellus to adjacent eye. Pronotum strongly and prominently curved on anterior margin, slightly declivous onward and bilaterally, striations definite. Scutellum triangular, with one light notch on each side of midline in posterior part, midline as long as pronotum. Forewings 
Fig. 6. Oncopsis spinosa sp. n. (a-h), $\mathrm{O}$. nigrofasciatus $\mathrm{Xu}$, Liang \& $\mathrm{Li}(\mathrm{i}-\mathrm{I}$, from 4 specimens) and $O$. furca Liu \& Zhang ( $m$ $\mathrm{n}$, from 2 specimens). - a. Male pygofer lobe and subgenital plate, lateral view. $-b$.

Aedeagus, lateral view. - c. Aedeagus, ventral view. - d, i-n. Dorsal connective, lateral view. - e. Style, dorsal view. - f. Connective, dorsal view. - g. Connective, lateral view. - h. $2^{\text {nd }}$ valvulae of ovipositor.
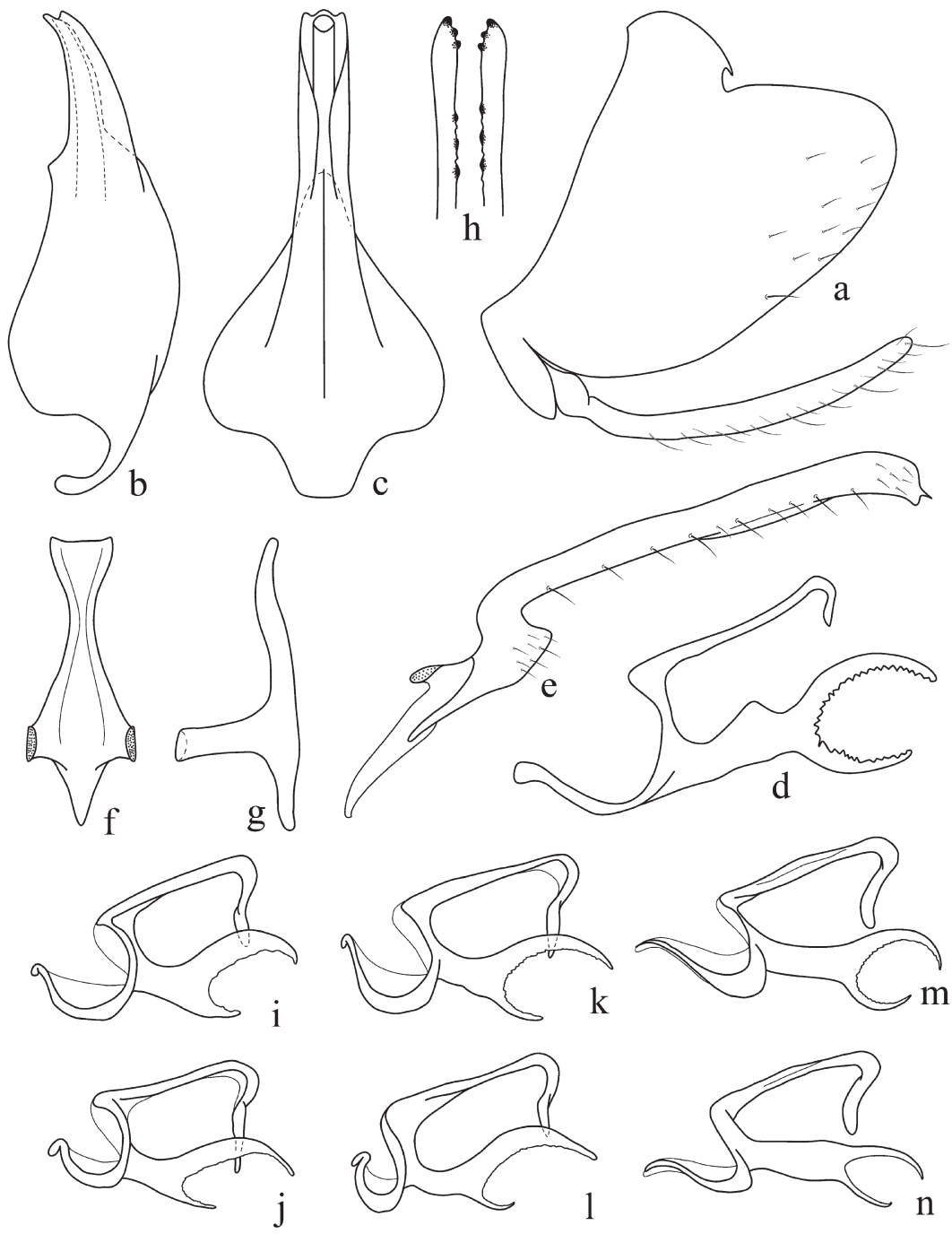

hyaline except dark brown half-hyaline regions, with 3 anteapical cells. $2^{\text {nd }}$ tergal apodemes wide and strong, with weak transverse striations on surface, apex truncated. $2^{\text {nd }}$ sternal apodemes broader basally, ends strongly sharpened, separated by relatively wide gap (Fig. 5b).

Coloration. Body brown, somewhat yellowish occasionally. Head brown, crown with a black transverse band. Face yellow, with a wide black transverse band, lower margin concave between eyes, clypellus black; eyes dark brown. Pronotum brown, striations dark brown. Scutellum yellow, both lateral areas with a black triangular mottle, posterior margin brown, midline black on anterior half, along with two black spots on central region. Forewings yellowish brown, with scattered

darker areas, veins dark brown. Legs yellowish.

Male genitalia. Pygofer oblong, slightly elongate, caudally truncated, on lateral lobes and ventral margin with several setae; subgenital plate slender with many marginal setae, slightly sinuate (Fig. 5a). Aedeagus tubular, broad basally, shaft slender, apex bifurcated with serrated margin, gonopore nearly apical (Figs. 5c-d). Dorsal connective strong, tip sinuate, bifurcated in middle, branch slender, twisted dorsally, bearing subapically small marginally serrated process, end serrated on dorsal margin (Fig. 5e). Style long with some setae, slightly sinuate, angled on apical third, apex slightly bulbous, produced to a digitation outside-dorsally (Fig. 5f). Connective similar to O. cuneiforma $\mathbf{s p .} \mathbf{n}$. 
Table 1. Main differences among three similar Oncopsis species.

\begin{tabular}{|c|c|c|c|}
\hline $\begin{array}{l}\text { Character/ } \\
\text { Structure }\end{array}$ & Oncopsis spinosa sp. $\mathbf{n}$. & $\begin{array}{l}\text { Oncopsis furca } \\
\text { Liu \& Zhang, } 2003\end{array}$ & $\begin{array}{l}\text { Oncopsis nigrofaciatus } \\
\text { Xu, Liang \& Li, } 2006\end{array}$ \\
\hline Body color & $\begin{array}{l}\text { Background yellowish } \\
\text { green in total, veins of } \\
\text { forewings yellowish green }\end{array}$ & $\begin{array}{l}\text { Background lemon yellow, } \\
\text { with black pigment on } \\
\text { pronotum and scutellum, } \\
\text { veins of forewings dark } \\
\text { brown }\end{array}$ & $\begin{array}{l}\text { Background yellowish } \\
\text { brown, with regular } \\
\text { maculae on pronotum and } \\
\text { scutellum, veins of } \\
\text { forewings dark brown }\end{array}$ \\
\hline $\begin{array}{l}\text { Length } \\
\text { (incl. tegmen) }\end{array}$ & $\begin{array}{l}\hat{\delta}, 4.5 \mathrm{~mm} \\
\stackrel{\mathrm{g}}{+} 4.6-4.8 \mathrm{~mm}\end{array}$ & $\hat{\sigma}, 4.9-5.0 \mathrm{~mm}$ & $\begin{array}{l}\text { त, } 3.2-3.5 \mathrm{~mm} \\
q, 3.4-3.8 \mathrm{~mm}\end{array}$ \\
\hline Aedeagus & Slender & $\begin{array}{l}\text { Slenderer than in } O \text {. } \\
\text { spinosa, especially on shaft }\end{array}$ & Stout \\
\hline Style & $\begin{array}{l}\text { Apex with additional } \\
\text { small spine }\end{array}$ & $\begin{array}{l}\text { Apex without additional } \\
\text { spine and not hook shaped }\end{array}$ & $\begin{array}{l}\text { Apex narrow and twisted } \\
\text { dorsad, hook shaped }\end{array}$ \\
\hline $\begin{array}{l}\text { Dorsal } \\
\text { connective }\end{array}$ & $\begin{array}{l}\text { Distinctly with } \\
\text { protuberance on basal part } \\
\text { of branch, basal part long, } \\
\text { two branches well } \\
\text { developed and far away } \\
\text { from each other }\end{array}$ & $\begin{array}{l}\text { Without protuberance on } \\
\text { basal part of branch, basal } \\
\text { part relatively long, two } \\
\text { branches well developed, } \\
\text { relatively close with each } \\
\text { other }\end{array}$ & $\begin{array}{l}\text { Without protuberance on } \\
\text { basal part of branch, basal } \\
\text { part distinctively short, } \\
\text { dorsal branch well } \\
\text { developed, ventral one less } \\
\text { developed and far away } \\
\text { from the upper one }\end{array}$ \\
\hline $\begin{array}{l}\text { Material } \\
\text { examined }\end{array}$ & See type material below & $\begin{array}{l}2 \lesssim \widehat{\partial}, \text { China: Qinghai } \\
\text { prov., Beishan, 3,000 m. }\end{array}$ & 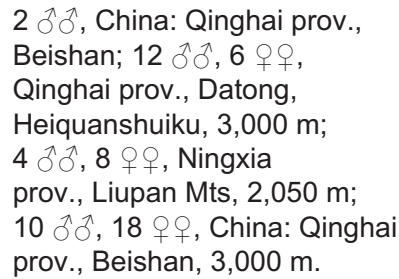 \\
\hline
\end{tabular}

Female. Body coloration and appearance similar to male, but more light and stout. Midline length of $7^{\text {th }}$ sternite about 1.2 times longer than $6^{\text {th }}$ sternite, concave in mid-posterior margin; ovipositor definitely projecting beyond pygofer (Fig. 1aa). $2^{\text {nd }}$ valvulae with weakly serrated inner margin (Fig. 5i).

Measurements. Length (including tegmen): $\widehat{\sigma}$ (holotype), $4.0 \mathrm{~mm}$; + (Paratype), $4.5 \mathrm{~mm}$.

Distribution. China (Ningxia prov.).

Remark. Closely similar to O. cuneiforma $\mathbf{s p .}$ n., but can be distinguished from the latter by: apex of aedeagus bifurcated with serrated margin; peculiar dorsal connective with slender branch, ended by serrated margin dorsally, and produced into another process subapically; apex of style without additional small spine.

Etymology. The name is derived from the Latin word "serrulotus", indicating the serrated apical margin of aedeagus.

\subsection{Oncopsis spinosa sp. n. (Fig. 1, Fig. 6)}

Type material. Holotype $\sigma^{1}$ : China: Qinghai prov., Beishan, 3,000 m, 5.VII.2008, leg. Yang Maofa. Paratypes, 4 오: same data as holotype.

Description. Male. (Body: Figs. 1e, m) Head relatively long with parallel margins, slightly curved prominently, wider than pronotum. Face (Fig. 1u) with weak striations; distance between ocelli 5 times as long as that from ocellus to adjacent eye; lora covered by frontoclypeus. Pronotum curved strongly and prominently, declivous onward and bilaterally, transverse striations weak. Scutellum triangular, margins straight, median length longer than that in pronotum. Forewing transparent, with 3 subapical cells.

Coloration. Body yellowish green. Head yellowish green, with two symmetric black spots. Face yellowish, frontoclypeus with a wide slender "U" shaped black band; clypellus brown; 
Fig. 7. Oncopsis kuluensis Viraktamath. - a. Male pygofer lobe and subgenital plate, lateral view. $-b$. $2^{\text {nd }}$ abdominal apodemes. - c. Aedeagus, lateral view. $-\mathrm{d}$. Aedeagus, ventral view. - e. Dorsal connective, lateral view. - f. Style, dorsal view. - g. Connective, dorsal view. - h. Connective, lateral view. $-\mathrm{i}$. $2^{\text {nd }}$ valvulae of ovipositor.
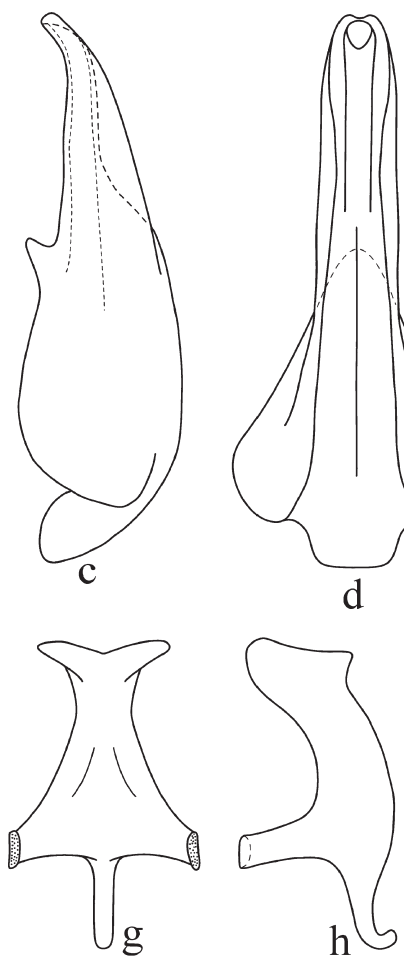

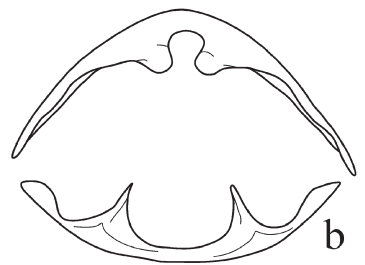

i

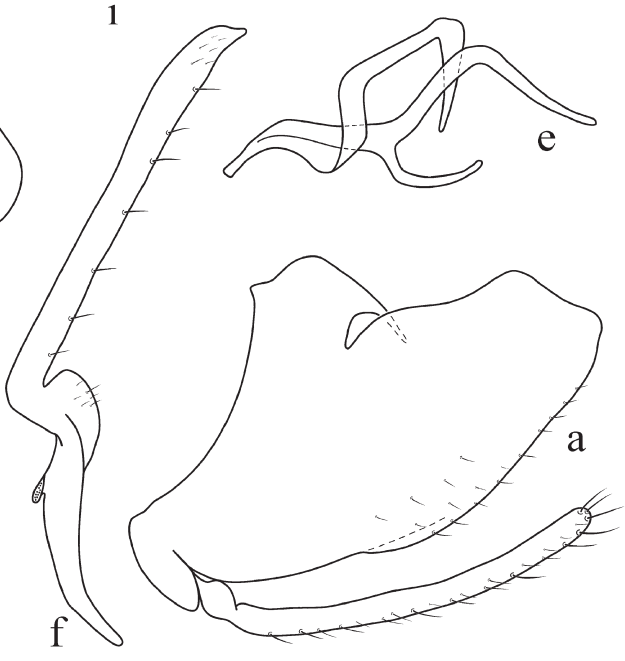

eyes red brown. Pronotum yellowish green, near eyes marked with brown mottles. Scutellum yellowish green with two symmetric black spots on central region, margins brown. Forewings slightly green, veins yellowish green. Legs yellowish marked with black spots occasionally.

Male genitalia. Pygofer broad, nearly triangular, caudal margin round, with several setae caudo-ventrally, subgenital plate slender with setae marginally (Fig. 6a). Aedeagus tubular, broader basally, in lateral aspect tapering, basally prominent ventrally, in ventral aspect, apex with a dent, shaft with paralleled margin, apical margin serrated; gonopore apical (Figs. 6b-c). Dorsal connective strong and large, with a middle protrusion of a long process with protuberance basally, tip bifurcated, inner margin serrated (Fig. 6d). Style slender, angled on apical third, with a protrusion in middle, tip sharpened with an additional spine (Fig. 6e). Connective moderately slenderer (Figs. 6f-g).

Female. Body coloration and appearance similar to male, but more intensive. $7^{\text {th }}$ sternite wider than and length of midline longer than $6^{\text {th }}$ sternite, concave in mid-posterior margin; ovipositor strongly projecting beyond pygofer (Fig. 1ab). Inner margin of $2^{\text {nd }}$ valvulae serrated, definitely with 3 clear additional teeth (Fig. 6h).

Measurements. Length (including tegmen): $\widehat{\partial}$ (holotype), $4.5 \mathrm{~mm}$; + (4 paratypes), 4.6-4.8 mm.

Distribution. China (Qinghai prov.).

Remark. Closely resembles $O$. furca Liu \& Zhang, 2003 (Figs. 6m-n) and O. nigrofaciatus $\mathrm{Xu}$, Liang \& Li, 2006 (Figs. 6a-h), the distinctive characters are listed in Table 1.

Etymology. The name is derived from the Latin word "spinosus", indicating the apex of style with an additional spine.

\section{New record for China: Oncopsis kuluensis Viraktamath (Fig. 1, Fig. 7)}

Oncopsis kuluensis Viraktamath, 1996: 185-187.

Material examined. $3 \hat{\jmath}$ , China: Sichuan prov., Emei Mountains, Jinding, 7.VIII.1991, leg. Li

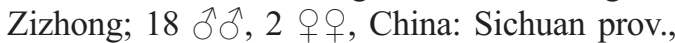
Emei Mountains, Leidongping, 7.VIII.1991, leg. 
Table 2. Distributions of Oncopsis species recorded in China.

\begin{tabular}{ll}
\hline Species name & Distribution \\
\hline Oncopsis alni (Schrank, 1801) & China (Xizang prov.), Japan, Europe \\
Oncopsis anchorous Xu, Liang \& Li, 2006 & China (Sichuan prov.) \\
Oncopsis aurantiaca Kuoh, 1992 & China (Yunnan prov.) \\
Oncopsis convexus Liu, 2009 & China (Shaanxi prov.) \\
Oncopsis cuneiforma Dai \& Li sp. n. & China (Yunnan prov.) \\
Oncopsis flavovirens Kuoh \& Chen, 1992 & China (Yunnan prov.) \\
Oncopsis fumosa Kuoh, 1992 & China (Yunnan prov.) \\
Oncopsis furca Liu \& Zhang, 2003 & China (Gansu prov.) \\
Oncopsis fusca (Melichar, 1902) & China (Xizang, Sichuan, Hubei prov.), Philippines, \\
& Malaysia \\
Oncopsis kangdingensis Dai \& Li sp. n. & China (Sichuan prov.) \\
Oncopsis melichari Lauterer \& Anufriev, 1969 & China (Sichuan prov.) \\
Oncopsis nigrofasciatus Xu, Liang \& Li, 2006 & China (Qinghai prov.) \\
Oncopsis obstructa Dlabola, 1963 & China (Xinjiang prov.), all regions of Tien Shan \\
& and Pamiro-Alai \\
Oncopsis odontoidea Dai \& Li sp. n. & China (Qinghai, Shaanxi, Ningxia prov.) \\
Oncopsis serrulota Dai \& Li sp. n. & China (Ningxia prov.) \\
Oncopsis spinosa Dai \& Li sp. $\mathbf{n}$. & China (Qinghai prov.) \\
Oncopsis kuluensis Viraktamath, 1996 & China (Sichuan prov.), India \\
Oncopsis testacea Kuoh, 1992 & China (Yunnan prov.) \\
Oncopsis trimaculata Kuoh, 1992 & China (Sichuan prov.) \\
Oncopsis tristis (Zetterstedt, 1840) & Transpalaearctic: China (Sichuan prov.), Europe, \\
& Russia, Mongolia, Japan \\
&
\end{tabular}

\section{Li Zizhong.}

Description. Body form, coloration and male genitalia in specimens from China as described in details by Viraktamath (1996).

$2^{\text {nd }}$ tergal apodemes short and small, close to each other; $2^{\text {nd }}$ sternal apodemes broader basally, parallel with each other, tapering, end sharpened (Fig. 7b).

Female. Body coloration and appearance similar to male, but more stout. Midline length of $7^{\text {th }}$ sternite about 3.0 times longer than that of $6^{\text {th }}$ sternite, deep concave on mid-posterior margin; ovipositor strongly projecting beyond pygofer (Fig. 1ac). $2^{\text {nd }}$ valvulae with 6 additional strong teeth (Fig. 7i).

Measurements. Length (including tegmen): $\hat{\sigma}$ $(n=10), 4.5-4.8 \mathrm{~mm}$; $+(n=2), 4.8-5.2 \mathrm{~mm}$.

Distribution. China (Sichuan prov.), new record; India.

Remark. This species can be easily identified by the following features: the head is narrower than pronotum; face definitely with inflated lower area of frontoclypeus, possessing unique truncated pygofer lobe in lateral view; apex of aedeagal shaft with a dent in ventral aspect, not sharpened but truncated or blunt in lateral aspect; discriminatively strongly developed dorsal connectives with bifurcated processes long and large.

\section{Key to Oncopsis species in China}

The distributions of the Oncopsis species in China have been presented in Table 2 .

1. Face between eyes as long as broad O.fusca

- Face between eyes longer than broad (Figs. 1q-x) 2

2. Apex of aedeagal shaft with a pair of processes on ventral margin O. aurantiaca

- Apex of aedeagal shaft without processes on ventral margin (Figs. $2 \mathrm{c}-\mathrm{d}, 3 \mathrm{c}-\mathrm{d}, 4 \mathrm{c}-\mathrm{d}, 5 \mathrm{c}-\mathrm{d}$, $6 \mathrm{~b}-\mathrm{c}, 7 \mathrm{c}-\mathrm{d})$

3

3. In lateral aspect aedeagal shaft slenderer and parallel margined, apex slightly inflated

O. melichari

- In lateral aspect aedeagal shaft less slender, more or less tapered (Figs. $2 c-d, 3 c-d, 4 c-d$, $5 \mathrm{c}-\mathrm{d}, 6 \mathrm{~b}-\mathrm{c}, 7 \mathrm{c}-\mathrm{d})$

4. Processes of dorsal connectives bifurcated (Figs. 3e, 4g, 5e, 6d, 6i-n, 7e) 
- Processes of dorsal connectives not bifurcated (Fig. 2e)

5. Processes of dorsal connectives long and wide, with serrated margins ventrally (Fig. 2e). O. cuneiforma sp. n.

- Processes of dorsal connectives slender, without serrated margins ventrally O.flavovirens

6. Branches of processes of dorsal connectives closed from basis to apex

O. testacea

- Branches of processes of dorsal connectives far away from each other (Figs. 3e, 4g, 5e, 6d, 6i-n, 7e)

7. Both branches long and distinct, well-developed (Figs. 3e, 6d, 6i-n, 7e)

- Upper branch small and short, sometimes almost reduced (Fig. 4g, 5e) 8

8. Upper branch located basally (Fig. 4g) O. odontoidea sp. n.

- Upper branch located subapically (Fig. 5e) O. serrulota sp. n.

9. Upper branch twisted to dorsum

- Upper branch twisted to ventrade (Figs. 3e, 6d, 6i-n, 7e)

10. Both branches with serrated inner margin (Figs. 3e, 6d, 6i-1,)

- Both branches without serrated inner margin (Figs. 6m-n, 7e)

11. Median aedaegal shaft slightly inflated

O. anchorous

- Median aedeagal shaft not inflated (Figs. 7cd)

12. Upper branch clearly shorter than nether one, tip sharpened

O. obstructa

- Upper branch longer than nether one, tip more or less blunt (Figs. 6m-n)

13. Base of dorsal connective branch relatively long, two branches relatively close with each other (Figs. 6m-n)

O. furca

- Base of dorsal connective branch relatively short, two branches relatively away from each other (Fig. 7e)

14. Dorsal connective large, both branches long, basally slender (Fig. 7e)

O. kuluensis

- Dorsal connective relatively small, both branches short, basally wide O.tristis

15. Upper branch of dorsal connective process longer than nether one (Figs. 6d, $\mathrm{i}-1$ )

- Upper branch of dorsal connective process shorter than nether one (Fig. 3e)

O. kangdingensis sp. n.
16. Base of dorsal connective process relatively long, with additional protuberance basally (Fig. 6d) O. spinosa sp.n.

- Base of dorsal connective process relatively short, without any protuberance (Figs. 6i-1)

O. nigrofasciatus

17. Aedeagus with a longitudinal carina basally in ventral aspect

O. trimaculata

- Aedeagus without a longitudinal carina basally in ventral aspect $\quad 18$

18. Dorsal connective processes bifurcate at basis part

- Dorsal connective processes bifurcate near basis part

O. alni

19. Apex of aedeagal shaft curved prominently

O. fumosa

- Apex of aedeagal shaft concave O.convexus

Acknowledgements. We thank two anonymous referees for reading the manuscript and making some constructive suggestions. We are very grateful to Prof. G. A. Anufriev ("Kerzhenskiy" State Biosphere Reserve, Nizhniy Novgorod, Russia) and Dr. Shigeru Okudera (Entomological Laboratory, Faculty of Agriculture, Kyushu University, Fukuoka, Japan) for some valuable suggestions and offering important literature, Dr. D. Yu. Tishechkin (Department of Entomology, Faculty of Biology, M. V. Lomonosov Moscow State University, Vorobyevy Gory, Moscow, Russia) and Prof. K. G. A. Hamilton (Eastern Cereal and Oilseed Research Centre, Ottawa, Ontario, Canada) for sending necessary literature. We also thank Prof. Maofa Yang (GUGC), Ms Qiongzhang Song (GUGC), Dr. Zaihua Yang (GUGC) and Dr. Yi Tang (GUGC) for providing material specimens for study. This project was supported by the National Natural Science Foundation of China (31000952).

\section{References}

Anufriev, G. A. 1967: Notes on the genus Oncopsis Burmeister, 1838 (Homoptera, Auchenorrhyncha) with descriptions of new species from the Soviet Far East. — Entomologisk Tidskrift 88(3-4): 174-184.

Anufriev, G. A. \& Emeljanov, A. F. 1988: Suborder Cicadinea (Auchenorrhyncha). — In: Lehr, D. A. (ed.), Keys to Insects of the Far East of the USSR Vol II: 12 495. Nauka Publishing House, Leningrad, USSR. 972 pp.

Dai, W. \& Zhang, Y. L. 2009: The genus Pediopsoides Matsumura (Hemiptera: Cicadellidae, Macropsini) from Mainland China, with description of two new species. - Zootaxa 2134: 23-35.

Hamilton, K. G. A. 1980: Contributions to the study of the world Macropsini (Rhynchota: Homoptera: Cicadellidae). — The Canadian Entomologist 112: 875-932. 
Hamilton, K. G. A. 1983: Revision of the Macropsini and Neopsini of the New-World (Rhynchota: Homoptera: Cicadellidae), with notes on intersex morphology. Memoirs of the Entomological Society of Canada 123: 5-222.

Korolevskaya, L. L. 1984: A new species of the genus Oncopsis (Auchenorrhyncha, Cicadellidae) from Tadjikistan. - Zoologicheskii Zhurnal 63: 622-623. [In Russian, English summary.]

Kuoh, C. L. 1981: Homoptera: Cicadelloidea. — In: Chinese Academy of Science (ed.), The Comprehensive Scientific Expedition to the Qinghai-Xizang Plateau, Insects of Xizang Vol. I.: 195-219. Science Press, Beijing, China. 600 pp. [In Chinese, English summary.]

Kuoh, C. L. 1985: Homoptera: Cicadelloidea. — In: Academia Sinica (ed.), The Mountaineering and Scientific Expedition, Biology of the Mt. Tuomuer areas in Tianshan: 82-89. Xinjiang people's press, Urumqi, China. 353 pp. [In Chinese, English summary.]

Kuoh, C. L. 1987. Homoptera: Cicadelloidea. — In: Zhang, S. M. (ed.), Agricultural insects, spiders, plant diseases and weeds of Xizang Vol. I.: 107-132. Xizang People's Press, Lhasa, China. 463 pp. [In Chinese, English summary.]

Kuoh, C. L. 1992. Homoptera: Cicadelloidea. — In: Chinese Academy of Science (ed.), The Comprehensive Scientific Expedition to the Qinghai-Xizang Plateau, Insects of the Hengduan Mountains Region Vol. I.: 243-316. Science Press, Beijing, China. 865 pp. [In Chinese, English summary.]

Lauterer, P. \& Anufriev, G. A. 1969: Contribution to the knowledge of the genus Oncopsis Burm. (Homoptera: Cicadellidae) from China and Far East. - Acta Musei Moraviae 54: 161-168.

Liu, Z. J. \& Zhang, Y. L. 2003: Description of Two New Species of Macropsinae (Homoptera: Cicadellidae) from China. - Entomotaxonomia 25(3): 181-185. [In Chinese, English summary.]
Liu, Z. J. 2009: Description of a new species of the genus Oncopsis (Homoptera: Cicadellidae: Macropsinae) from Mt Taibai, Shaanxi Province, China. — Forest Pest and Disease 28(5): 15-16. [In Chinese, English summary.]

Mühlethaler, R. 2008: Description of a new species of the genus Oncopsis (Hemiptera: Cicadomorpha: Cicadellidae) from Greece. - Acta Entomologica Slovenica 16(1): 5-10.

Okudera, S. 2008: Six new species of the leafhopper genus Oncopsis (Auchenorrhyncha, Cicadellidae, Macropsinae) from Japan. - Japanese Journal of Systematic Entomology 14(2): 191-205.

Tishechkin, D. Y. 1992: A new species of Oncopsis (Homoptera, Cicadinea, Cicadellidae) from the Northern Caucasus. - Zoologicheskii Zhurnal 71: 141-144. [In Russian; English summary.]

Tishechkin, D. Y. 2008: A new species of Oncopsis from the $O$. flavicollis (Linnaeus, 1761) species group (Homoptera: Cicadellidae: Macropsinae) from Eastern Siberia. - Russian Entomological Journal 17(2): 139_ 143.

Tishechkin, D. Y. 2011: New Data on the Taxonomy of Middle Asian Macropsinae (Homoptera, Cicadellidae) - Zoologicheskii Zhurnal 90(6): 688-697. [In Russian, English translation: Entomological Review, 2011, 91(5): 624-633.]

Viraktamath, C. A. 1996: New Oriental Macropsinae with a key to species of the Indian subcontinent (Insecta: Auchenorrhyncha: Cicadellidae). — Entomologische Abhandlungen, Stätliches Museum für Tierkunde, Dresden 57(7): 183-200.

Xu, P., Liang, A. P. \& Li, Z. Z. 2006: Descriptions of two new species of Oncopsis Burmeister (Hemiptera, Cicadellidae, Macropsinae) from China. - Acta Zootaxonomica Sinica 31(4): 835-839. [In Chinese; English summary.] 